\title{
Effect of Extrusion Parameters on Properties of Powder Coatings Determined by Infrared Spectroscopy
}

\author{
A. Lepschi ${ }^{1, *}, J^{*}$ Kilgus $^{2}$, M. Brandstetter ${ }^{2}$ and J. Miethlinger ${ }^{1}$ \\ ${ }^{1}$ Johannes Kepler University Linz, Altenbergerstraße 69, 4040 Linz, Austria \\ ${ }^{2}$ Research Center for Non Destructive Testing (RECENDT), Altenbergerstaße 69, 4040 Linz, Austria
}

\begin{abstract}
In polymer extrusion, compounding is a continuous mixing process that is also used to produce highly reactive powder coatings. A premixed batch of powder coating is added to the feeding section and extruded, preferably by a co-rotating twin-screw extruder. One essential parameter in the processing of highly reactive materials is the melt temperature: If it is too high, pre-reactions occur during the extrusion process, which may cause high rejection rates. We studied the melt temperature of an epoxy/carboxylbased powder coating using a retractable thermocouple at 3 different axial positions along the barrel of a ZSK34 co-rotating twin-screw extruder. The influence of different processing conditions on the reactivity of a highly reactive powder coating was examined by infrared spectroscopy and differential scanning calorimetry. Furthermore, the specific energy input and the color change in the finished powder coating at different processing points were investigated. Multivariate data analysis was used to correlate mid-infrared spectra, melt temperatures, specific energy inputs, enthalpies of reaction and changes in color.
\end{abstract}

Received on 18-05-2017 Accepted on 05-09-2017 Published on 05-10-2017

Keywords: Extrusion, twin screw, infrared spectroscopy, ATR, DSC.

\section{INTRODUCTION}

Optical measurement techniques are widely used to analyze chemical reactions and polymer compositions. Near-infrared (NIR) and mid-infrared (MIR) show different details of the chemical structure in different spectral ranges. NIR spectra (12500 to $4000 \mathrm{~cm}^{-1}$, corresponding to 0.8 to $2.5 \mu \mathrm{m}$ ) are often used to investigate polymer blends and curing kinetics or to predict mechanical properties [1-17]. In the NIR range, A. Kelly et al. [1] measured the drug and plasticizer content in a polymer melt. A sensor was placed in the die, and measurements were performed in transmittance. Other reactions such as the graft copolymerization of maleic anhydride on polypropylene were studied by L. Moghaddam [2]: A NIR spectrometer was connected via a fiber to a laboratory-scale extruder. To determine the effect of chain scission, NIR spectra and apparent viscosity were measured simultaneously. A. R. McLauchlin et al. studied the contamination of recycled polyethylene terephthalate by polylactid acid [3]. D. F. Barbin investigated the potential of VIS/near infrared spectroscopy as a tool for analyzing biodegradable films [4]. The spectra were analyzed by partial least squares (PLS) regression and the results used to predict mechanical properties such as elongation, tensile

"Johannes Kepler University Linz, Altenbergerstraße 69, 4040 Linz, Austria; Tel: +43 7322468 6580; E-mail: alexander.lepschi@jku.at strength and Young's modulus. T. Rohe et al. [5] investigated different compositions of polypropylene-polyethylene blends, measuring them inline in transmittance. A further field of application is quality control in hot melt extrusion [6, 7]. T. Scherzer et al. monitored the conversion of double bonds in acrylate of polymer foils after irradiation with UV light [9], and A. Almeida et al. used the measured spectra to compare a lab-scale extruder with a pilot-scale extruder [10]. Near infrared is often employed to determine the curing kinetics of thermosets. Based on NIR spectra, H. Howland et al. examined the degree of curing and monitored physicalmechanical changes [12]. The curing kinetics of epoxy resins at different heating rates were studied by $\mathrm{E}$. Duemichen et al. and $G$. Li $[13,14]$. The former demonstrated the influence of temperature on near infrared spectra. H. Yamasaki et al. used near infrared and differential scanning calorimetry (DSC) to investigate the curing reaction of epoxy resin [15, 16].

In polymer extrusion, the same properties have also been determined using light in the MIR spectral range (4000 to 400 $\mathrm{cm}^{-1}$ ) [21-26]. P.D. Coates et al. employed an online MIR setup to detect polymer blends based on polypropylene and polyethylene [21]. The blends were measured inline using near infrared and Raman and online using MIR and NIR in a single-screw extruder. Y. Kann demonstrated the possibility 
of analyzing the crystallinity of poly(3-hydroxybutyrate-co-4hydroxybutyrate) polymers and compared the results of the method to DSC measurements [19]. Z. Cui studied the application of attenuated total reflectance (ATR) Fourier transform infrared spectroscopy (FTIR) in a reductionpolymerization route for the synthesis of conducting poly $(3,4-$ ethylenedioxythiophene) polymers [20].

A commonly applied multivariate data analysis method used to predict material or process parameters on the basis of chemical information contained in infrared spectra is partial least squares (PLS) regression [24-29]. PLS is basically a combination of principal component analysis (PCA) and multiple linear regression (MLR). We used the PLS regression method incorporated into the OriginPro 2015G software (OriginLab Corporation, Northampton, USA). PLS is often used as a prediction tool and for reducing highly correlated variables, which is usually the case for NIR and MIR spectra, to a set of independent variables. The goal is to distinguish between dependent (endogenous) variables and independent (exogenous) variables and build a linear model. Latent variables are extracted to estimate the covariance of dependent and independent variables. The regression of the values is predicted from the dependent variables by separating them from the independent variables. To define a quantitative relation between latent variables, each latent variable must be defined by one or more indicators [31].

In this case study, MIR spectroscopy in combination with PLS regression was used to predict the influence of screw speed, mass throughput, specific energy input (SEI) and melt temperature on the reactivity and color of epoxy-based powder coatings. The color was evaluated using $\Delta E$ (i.e., the change of color in the CIE Lab color space) relative to sample 1, calculated according to:

$$
\Delta E=\sqrt{\Delta L^{2}+\Delta a^{2}+\Delta b^{2}}
$$

where $L$, a and b were $40.88,47.36$ and 25.81 , respectively. $\mathrm{CIE}$ Lab describes the lightness of a color, where $L$ is between black and white, $a$ is between red and green and $b$ is between blue and yellow.
The SEI describes the amount of energy needed for material processing and is defined as:

$S E I=\frac{P_{m e c h}}{\dot{m}}=\frac{M \omega}{\dot{m}}=\frac{M 2 \pi N}{\dot{m}}$

where $\mathrm{M}$ is the drive torque of the screws, $\mathrm{N}$ is the screw speed, and $\dot{m}$ is the mass throughput.

Models for the linear regressions were evaluated using the root mean square error (RMSE) and the coefficient of determination $R^{2}$ in equations (3) to (6). RMSE and $R^{2}$ are defined as:

$$
\begin{aligned}
& R^{2}=1-\frac{S_{\hat{u}}^{2}}{S_{y}^{2}} \\
& S_{y}=\sum_{i}\left(y_{i}-\bar{y}\right)^{2} \\
& S_{\hat{u}}=\sum_{i}\left(y_{i}-f_{i}\right)^{2} \\
& R M S E=\sqrt{E\left[(\hat{\theta}-\theta)_{2}\right]}
\end{aligned}
$$

where $\mathrm{E}$ is the expectation of an estimator $\hat{\theta}$ with respect to an unknown parameter $\theta, S_{\hat{u}}^{2}$ is the residual sum of squares, and $\mathrm{s}_{\mathrm{y}}$ is the total sum of squares [32].

\section{Infrared Spectroscopy}

The epoxy/carboxyl-based thermosets (Table 2) were measured by infrared spectroscopy. Figure 1 shows the samples for the measurements.

The samples were studied in the MIR range by means of ATR measurements. Figure 2 shows the principle of an ATR measurement setup. The emitted light passes the crystal and arrives at the crystal-sample interface, where it is totally reflected. If light passes from a material with a high refractive index to one with a low refractive index, total reflection will occur at a critical angle of incidence. However, at the interface between crystal and sample, light penetrates the

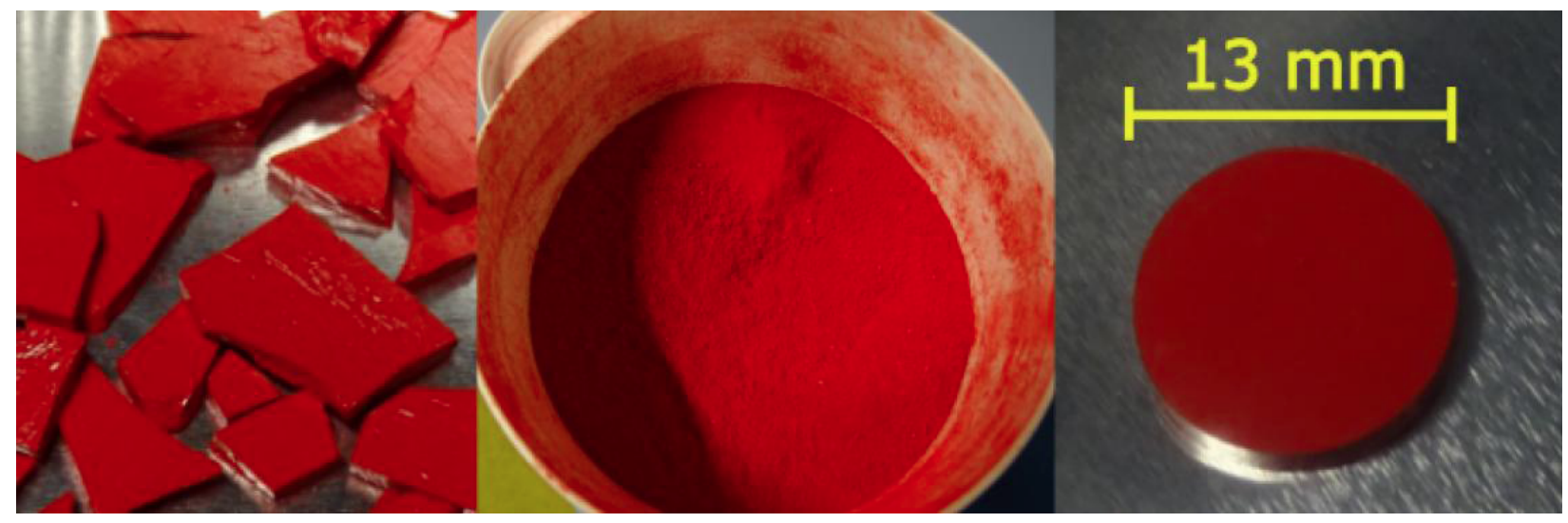

Figure 1: Epoxy/carboxyl samples - flakes (left), powder (center) and pressed powder tablets (right). 
sample and creates an evanescent field. The penetration depth is usually in the range of a few microns [33].

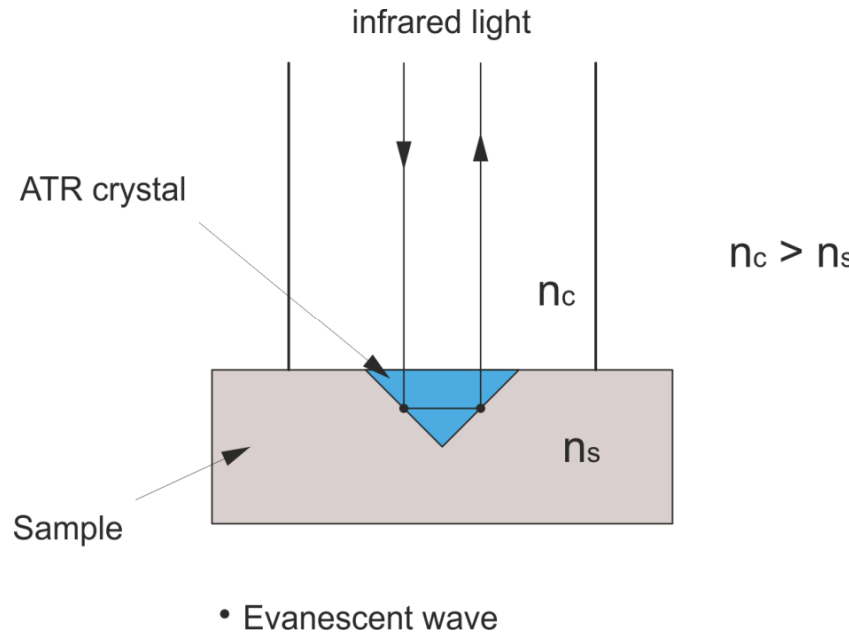

Figure 2: Principle of ATR measurements; $n_{s}$ and $n_{c}$ are the refractive indices of the sample and the crystal, respectively.

The incident angle $\Theta$ and the penetration depth $d_{p}$ can be defined as:

$\sin \Theta=\frac{n_{s}}{n_{c}}$

and

$d_{p}=\frac{\lambda_{0}}{2 \pi n_{c} \sqrt{\sin ^{2} \Theta-\left(\frac{n_{s}}{n_{c}}\right)^{2}}}$

where $n_{s}$ is the refractive index of the sample, $n_{c}$ is the refractive index of the crystal, and $\lambda_{0}$ is the wave length.

\section{EXPERIMENTAL}

A highly reactive epoxy resin was extruded using a ZSK34 co-rotating twin-screw extruder from Coperion. The melt temperatures were measured at two positions in the barrel (Figure 3) and at one position in the die (Figure 4). The processing points are listed in Table $\mathbf{1}$, and the schematic screw configurations are shown in Figure $\mathbf{5}$.

As mentioned above, all samples were produced at different screw speeds and mass throughputs. The reaction enthalpies of the extruded flakes and the final powder coating were measured by differential scanning calorimetry using a DSC822e from Mettler Toledo. The heating rate was $5 \mathrm{~K} / \mathrm{min}$ from $90^{\circ} \mathrm{C}$ to $200^{\circ} \mathrm{C}$. The color measurements were performed using a Datacolor 400 spectrophotometer.

Mass throughputs, screw speeds, reaction enthalpies, maximum melt temperatures and $\Delta E$ values are shown in Table 2. All melt temperatures from positions 1 to 3 are the maximum values measured during the production time of
Retractable melt thermocouple

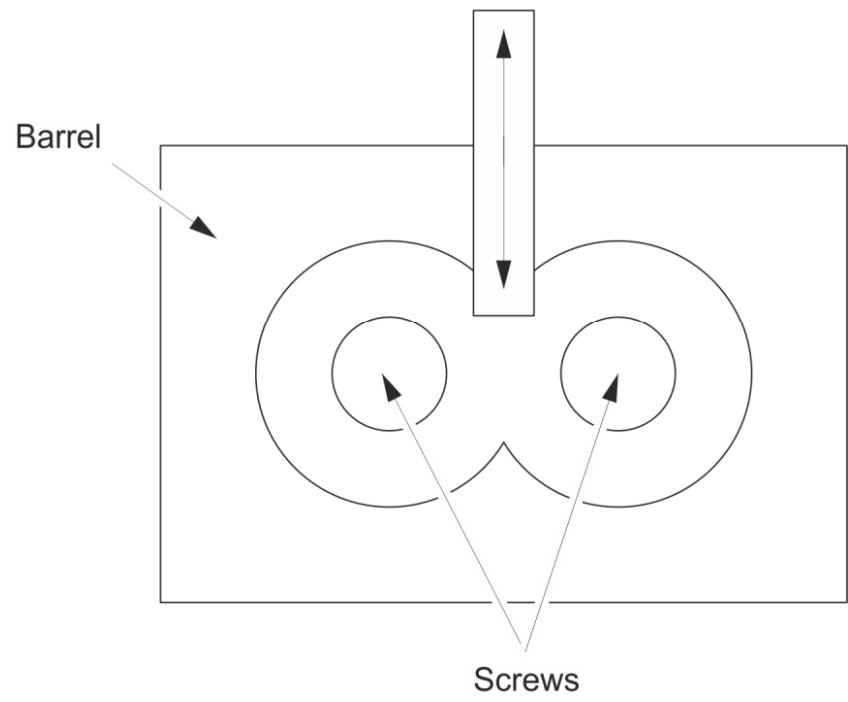

Figure 3: Measurement position of the retractable temperature sensor in the barrel.

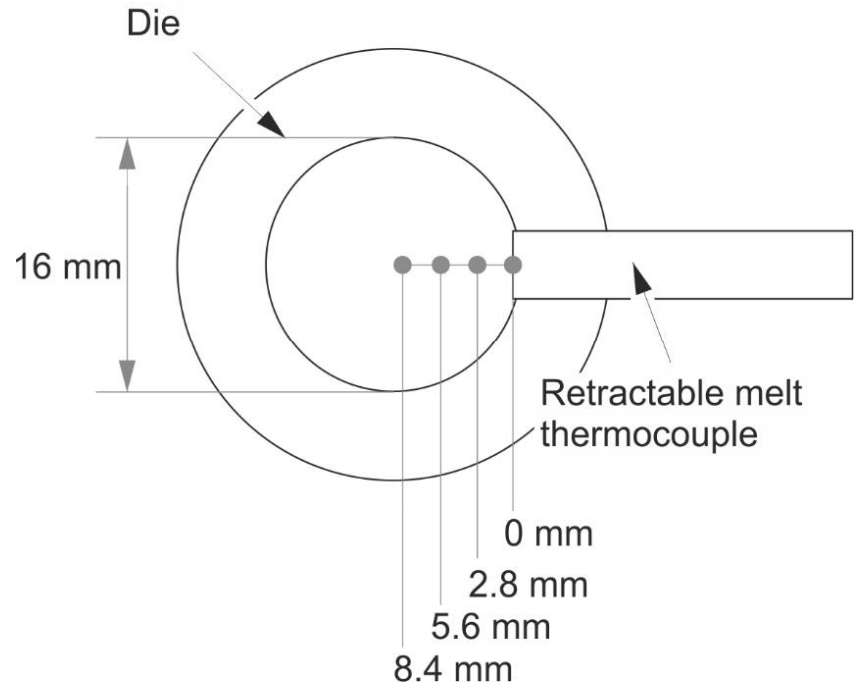

Figure 4: Measurement position of the retractable melt thermocouple in the die.

about 10 min per processing point. The $\Delta E$ values are given relative to sample 1 .

The data listed in Table 2 and the IR spectra of three samples at each processing point were used for PLS regression analysis. As the maximum melt temperatures of screw configurations $\mathrm{T} 1$ and $\mathrm{T} 2$ were similar, PLS regression was applied to samples 1 to 9 .

\section{RESULTS AND DISCUSSION}

The influence of mass throughput on the melt temperature is illustrated in Figure 6. Due to the shorter residence time at higher mass throughput, the maximum melt temperature decreased from approximately $145^{\circ} \mathrm{C}$ to $135^{\circ} \mathrm{C}$. The centers 
Feeding section

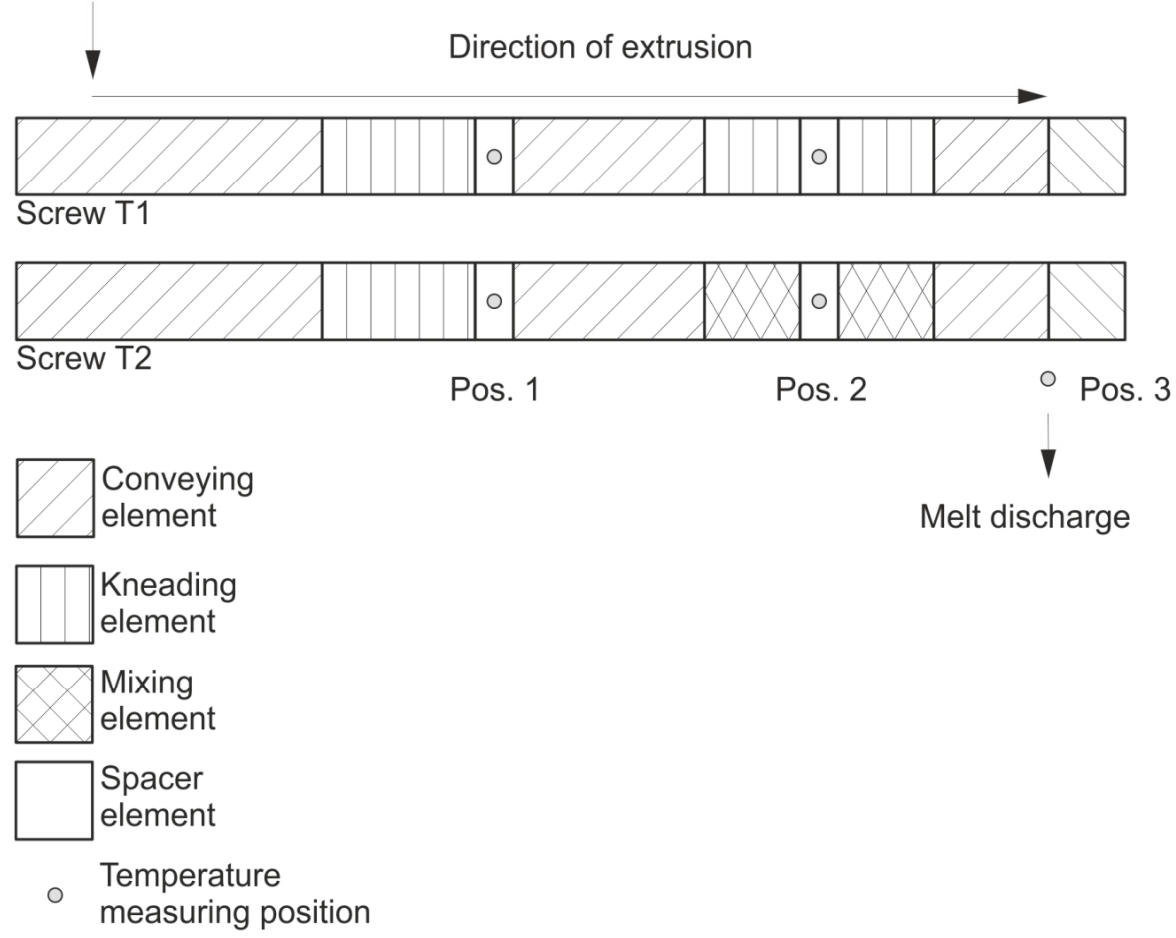

Figure 5: Screw configurations and measurement positions of the temperature sensor; length of spacer element: $14 \mathrm{~mm}$; total screw length: $24 \mathrm{~L}$ over D.

Table 1: Processing Points for Screw Configurations T1 and T2

\begin{tabular}{|c|c|c|c|}
\hline No. & Screw speed (rpm) & Throughput (kg/h) & Screw configuration \\
\hline 1 & 600 & 120 & $\mathrm{~T} 1$ \\
\hline 2 & 600 & 183 & $\mathrm{~T} 1$ \\
\hline 3 & 600 & 234 & $\mathrm{~T} 1$ \\
\hline 4 & 900 & 120 & T1 \\
\hline 7 & 1200 & 120 & T1 \\
\hline 8 & 1200 & 183 & T1 \\
\hline 9 & 1200 & 234 & T1 \\
\hline 10 & 600 & 120 & T2 \\
\hline 14 & 900 & 183 & $\mathrm{~T} 2$ \\
\hline 15 & 900 & 234 & T2 \\
\hline 16 & 1200 & 120 & $\mathrm{~T} 2$ \\
\hline 17 & 1200 & 183 & $\mathrm{~T} 2$ \\
\hline 18 & 1200 & 234 & T2 \\
\hline
\end{tabular}


Table 2: Processing Conditions, Reaction Enthalpies and Melt Temperatures - Samples 1 to 9

\begin{tabular}{|c|c|c|c|c|c|c|c|c|}
\hline No. & $\mathbf{N}(\mathbf{r p m})$ & $\dot{\mathbf{m}}(\mathbf{k g} / \mathbf{h})$ & Enthalpy: flakes $(\mathbf{J} / \mathbf{g})$ & Enthalpy: powder $(\mathbf{J} / \mathbf{g})$ & $\mathbf{T}_{\max }\left({ }^{\circ} \mathbf{C}\right)$ & $\mathbf{T 2}_{\max }\left({ }^{\circ} \mathbf{C}\right)$ & $\mathbf{T}_{\max }\left({ }^{\circ} \mathbf{C}\right)$ & $\Delta \mathbf{E}$ \\
\hline \hline 1 & 600 & 120 & 97.7 & 47.0 & 120 & 129 & 137 & 0.0 \\
\hline 2 & 600 & 183 & 20.0 & 35.8 & 116 & 123 & 133 & 0.9 \\
\hline 3 & 600 & 234 & 24.4 & 35.7 & 116 & 121 & 132 & 2.0 \\
\hline 4 & 900 & 120 & 20.8 & 33.0 & 129 & 140 & 146 & 1.0 \\
\hline 5 & 900 & 183 & 31.5 & 30.9 & 122 & 132 & 142 & 0.6 \\
\hline 6 & 900 & 234 & 40.5 & 32.7 & 119 & 130 & 139 & 1.4 \\
\hline 7 & 1200 & 120 & 33.5 & 32.0 & 135 & 153 & 155 & 1.2 \\
\hline 8 & 1200 & 183 & 18.8 & 29.8 & 128 & 140 & 150 & 0.9 \\
\hline 9 & 1200 & 234 & 20.1 & 27.9 & 136 & 142 & 148 & 1.0 \\
\hline
\end{tabular}

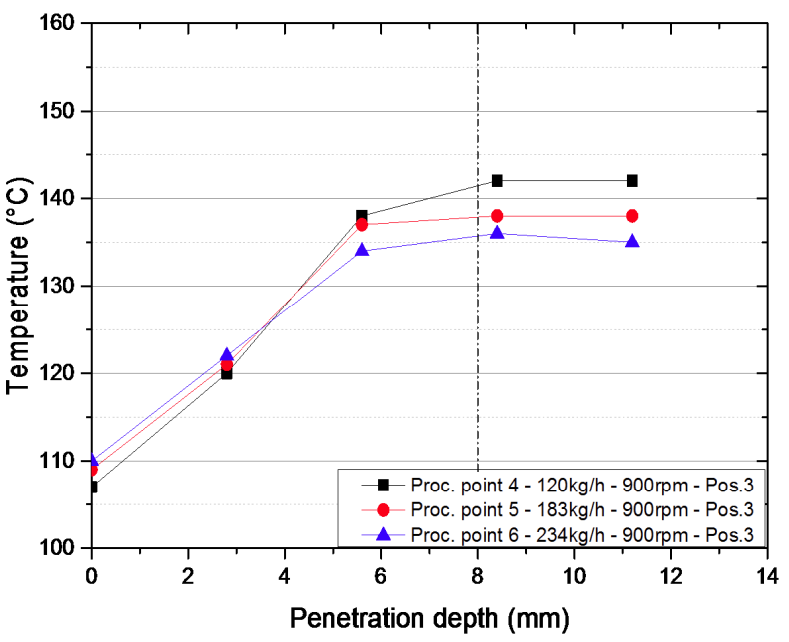

Figure 6: Temperature profile in the die - relationship between temperature and mass throughput at $900 \mathrm{rpm}$. Center of the die indicated by a dash-dotted line.

of the barrel (Pos. 1 and 2) and the die (Pos. 3) were at penetration depths of about 10.7 and $8 \mathrm{~mm}$, respectively.

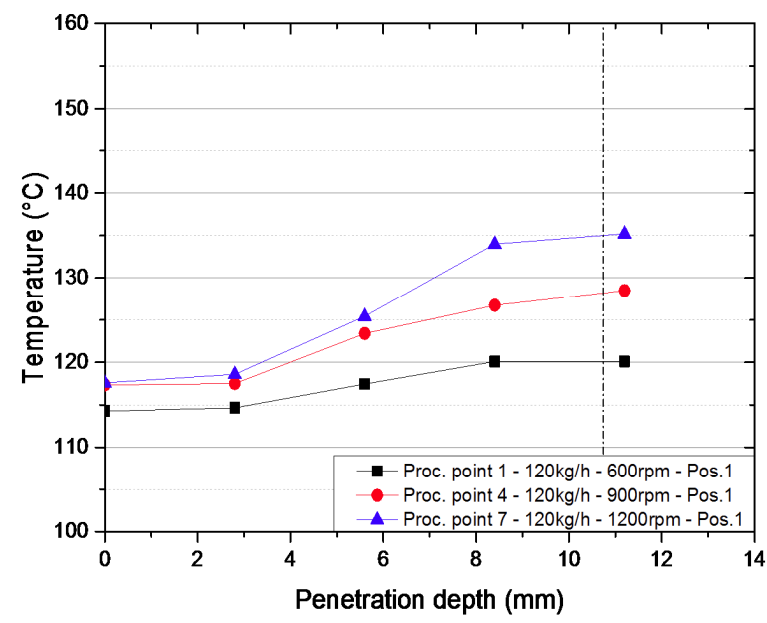

Figure 7: Relationship between temperature and screw speed measuring position 1 at $900 \mathrm{rpm}$. The center of the barrel is indicated by a dash-dotted line.

Figures 7 to 9 show the temperature increase from position 1 to position 3 in the twin-screw extruder. The channel height of the screw was about $7.5 \mathrm{~mm}$. The maximum melt temperature increased by about $10^{\circ} \mathrm{C}$ from position 1 to position 2 and by about $6^{\circ} \mathrm{C}$ from position 2 to position 3 .

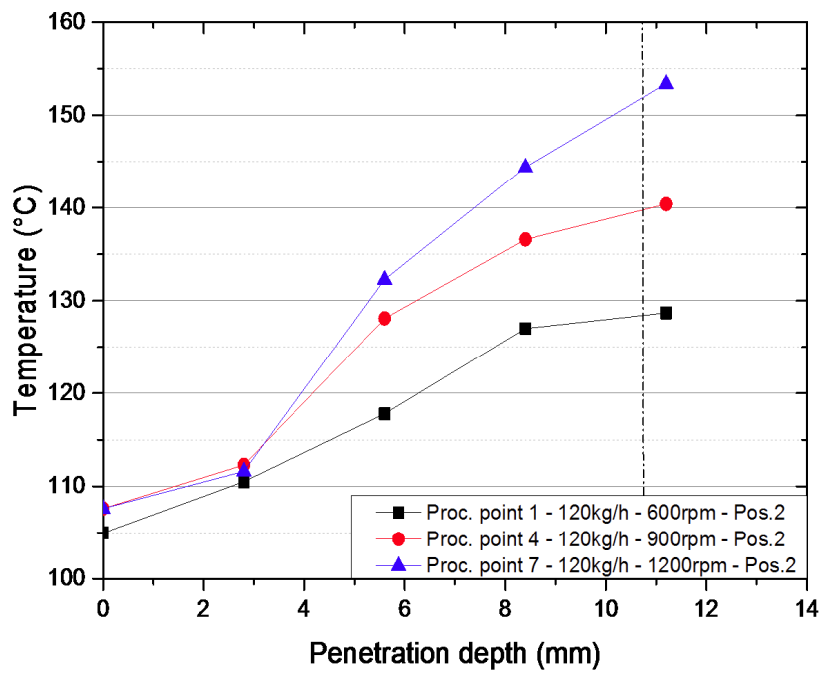

Figure 8: Relationship between temperature and screw speed measuring position 2 at $900 \mathrm{rpm}$. The center of the barrel is indicated by a dash-dotted line.

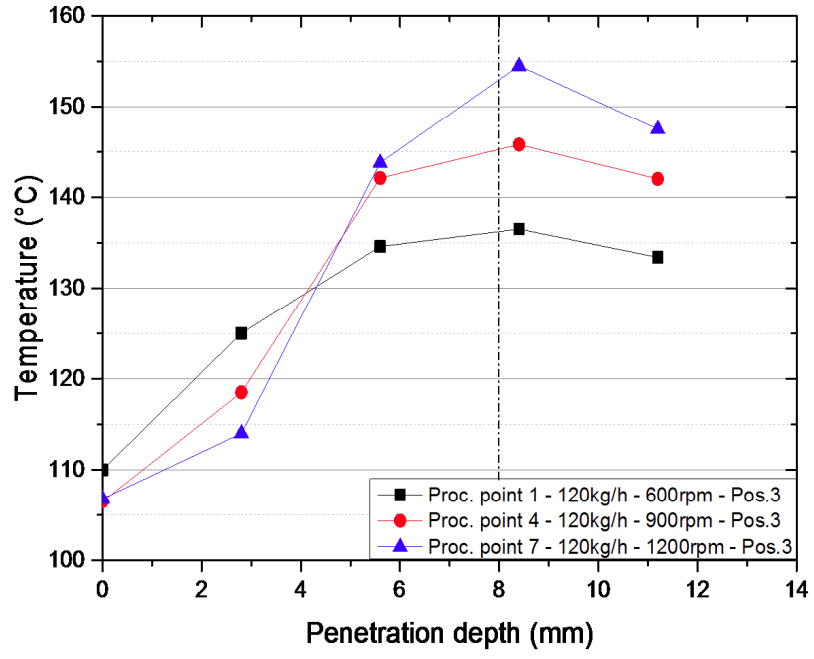

Figure 9: Relationship between temperature and screw speed measuring position 3 . The center of the barrel is indicated by a dashdotted line. 
An increase in screw speed of $300 \mathrm{rpm}$ resulted in a temperature increase of between $6^{\circ} \mathrm{C}$ and $9^{\circ} \mathrm{C}$ (Figure 9) in the die, whereas increasing the throughput by $60 \mathrm{~kg} / \mathrm{h}$ decreased the melt temperature by about $4^{\circ} \mathrm{C}$ in the die (Figure 6). The mixing elements used slightly increased the maximum melt temperature and led to a more homogeneous melt temperature (Figure 10). The difference between minimum and maximum melt temperature $\Delta T$ decreased.

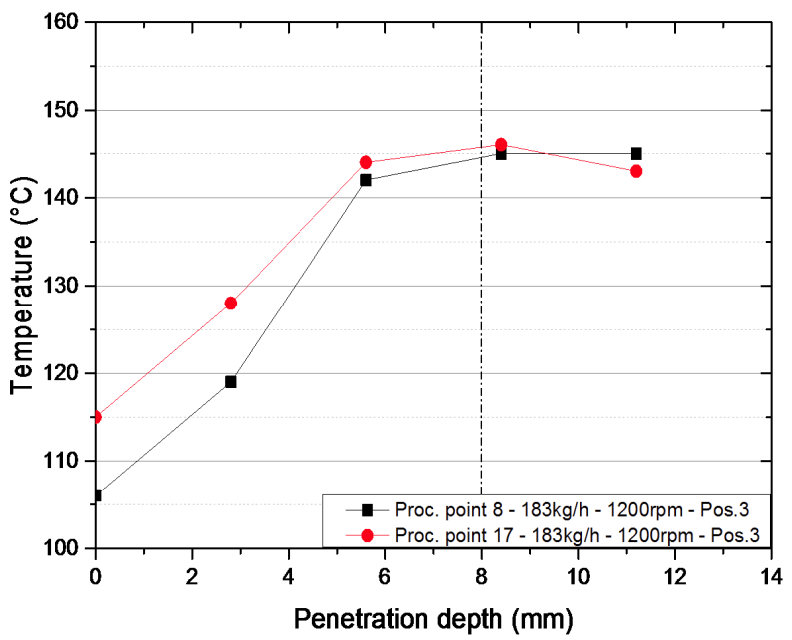

Figure 10: Relationship between temperature and screw configuration.

The reaction enthalpy was measured by DSC before and after milling. The results are illustrated in Figure 11 (flakes) and Figure 12 (powder). High melt temperatures resulted in a low reaction enthalpy, and inhomogeneous temperature profiles led to increased variability in the samples. Further, milling decreased the enthalpy of reaction. Figure 13 shows the difference in the infrared spectra between the premix and the extruded samples (flakes and pressed powder tablets). Due to the high energy input of the mill, the chemical structure of the powder coating changed. On the one hand, homogenization improved, but on the other a decrease in the enthalpy of reaction was observed, indicating pre-reaction in the mill.

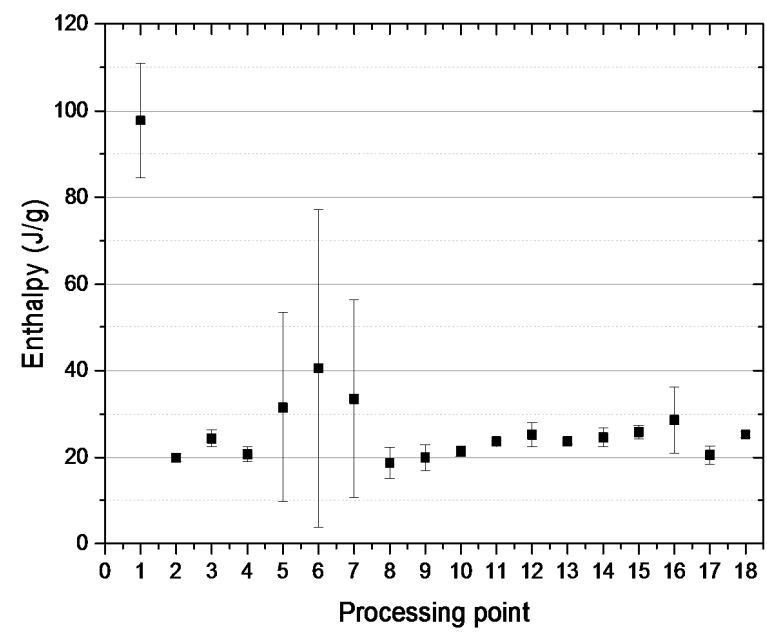

Figure 11: Enthalpy of reaction - flakes.

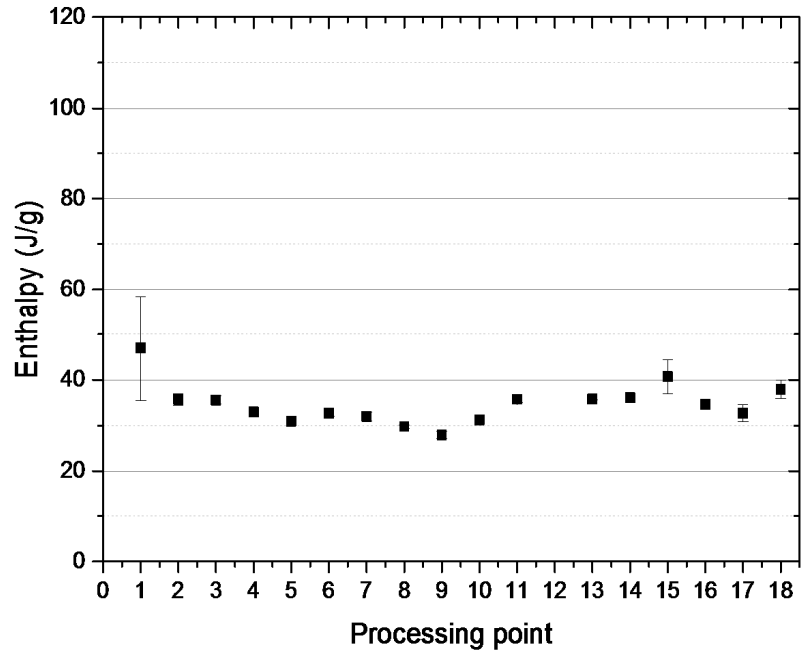

Figure 12: Enthalpy of reaction - powder.

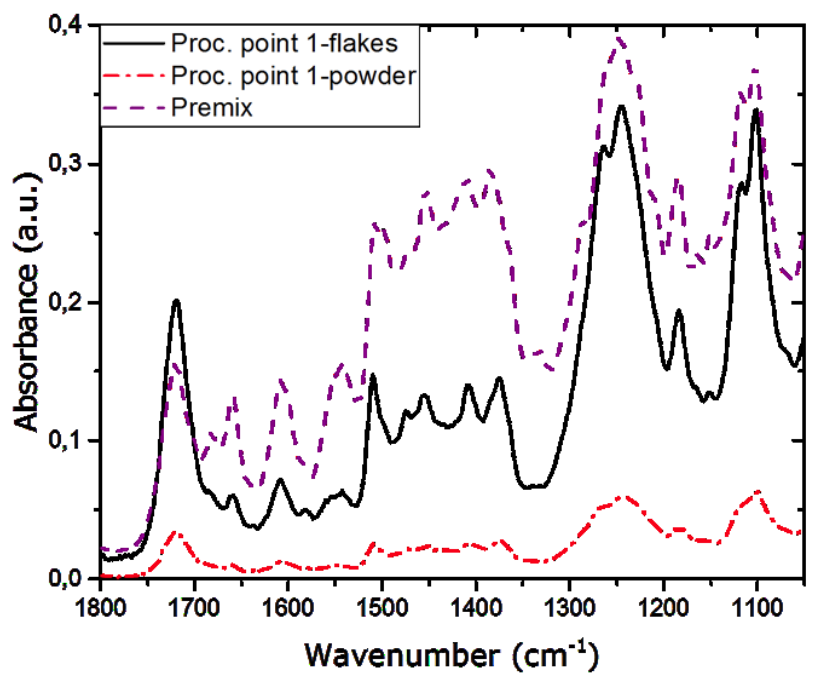

Figure 13: ATR measurements of premix and the extruded samples at processing point 1 .

Figure 14 shows the difference in the infrared spectra between the premix and the extruded samples (flakes and pressed powder tablets). Due to the high energy input of the mill, the chemical structure of the powder coating changed. On the one hand, homogenization improved, but on the other a decrease in the enthalpy of reaction was observed, indicating pre-reaction in the mill.

Since different processing points led to different melt temperatures and residence times in the extruder, we expected different reaction enthalpies and thus different chemical states of the finished powder coatings. We investigated, whether this information can be extracted from MIR absorption spectra. Relevant sections of the corresponding absorptions spectra are plotted in Figure 14. The spectra shows a significant difference in absorbance between premix and extruded samples. To determine the influence of different processing conditions, the PLS method was used to examine the spectra. 

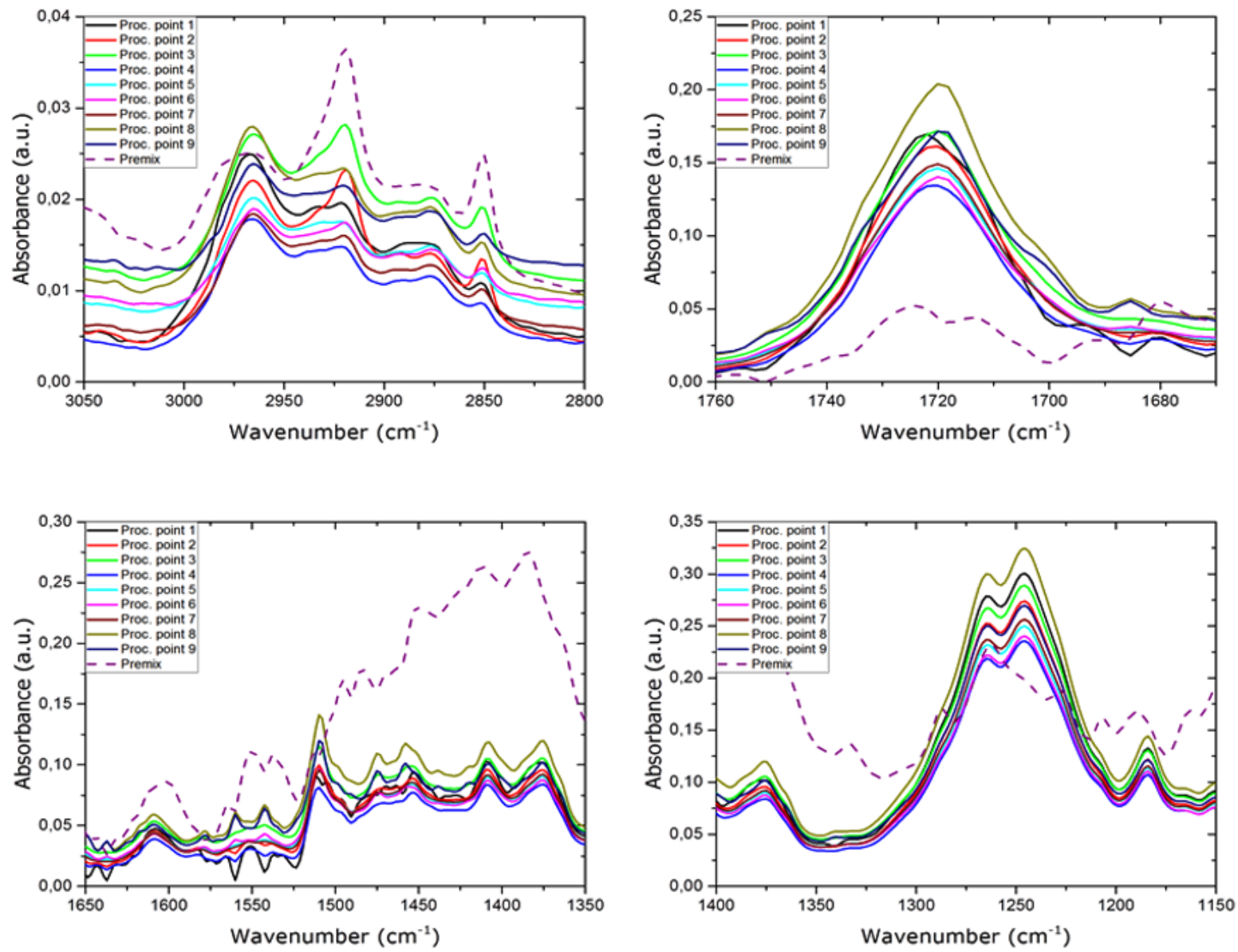

Figure 14: ATR measurements of pressed powder tablets at different wavenumbers.

Table 3: $\quad \mathbf{R}^{2}$ and RMSE of Cross-Validation for the Multivariate Linear Regression Models

\begin{tabular}{|c|l|c|}
\hline Model. & $\mathbf{R}^{2}$ & RMSE \\
\hline \hline Throughput & 0.98614 & 6.1985 \\
\hline Screw speed & 0.99919 & 7.2447 \\
\hline Enthalpy:flakes & 0.98774 & 2.7122 \\
\hline Enthalpy:powder & 0.99358 & 0.4347 \\
\hline$T 1_{\max }$ & 0.97948 & 1.0818 \\
\hline$T 2_{\max }$ & 0.98977 & 1.0235 \\
\hline $\mathrm{T} 3_{\max }$ & 0.98991 & 0.7670 \\
\hline $\mathrm{SEI}$ & 0.99054 & 0.0024 \\
\hline$\Delta \mathrm{E}$ & 0.97760 & 0.0793 \\
\hline
\end{tabular}

The multivariate linear PLS regression models (calculated from the ATR absorbance spectra of the samples) of throughput, screw speed, maximum melt temperatures at positions 1 to 3 , SEI and $\Delta E$ value are illustrated in Figure 15. A Savitzky-Goly filter and the $1^{\text {st }}$ derivative were used for preprocessing the recorded spectral data. Cross-validation of the PLS models was performed using leave-one-out cross validation. The resulting PLS regression models show a coefficient of determination above 0.97 and high predicted value accuracy.

\section{CONCLUSION}

We have shown that infrared spectroscopy is well suited to quantify the influence of different processing conditions of extruded epoxy-based powder coatings. Combining ATR with multivariate data analysis to determine color change, specific energy input and the reactivity of the powder coating yielded results that showed good correlation with measurements. Further, it is possible to verify the influence of the processing conditions on the melt temperature at different axial positions 

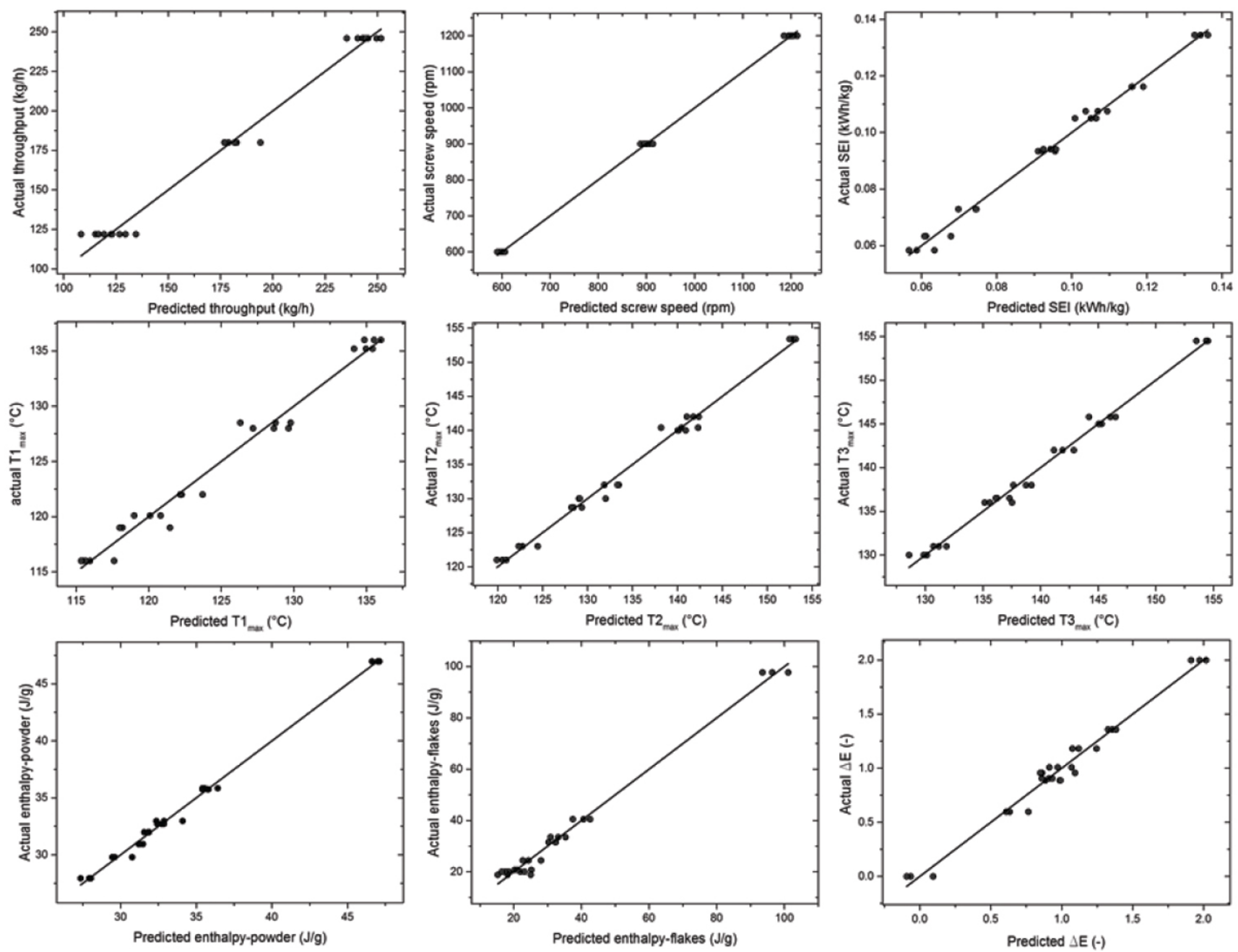

Figure 15: Predicted vs. Actual throughput, screw speed, melt temperatures, enthalpy, SEI and $\Delta \mathrm{E}$ computed by PLS regression.

along the barrel. The importance of color as a parameter in powder coatings makes the ability to examine $\Delta E$ values before the coating process of great potential interest.

\section{REFERENCES}

[1] Kelly AL, Halsey SA, Bottom RA, Korde S, Gough T, Paradkar A. A novel transflectance near infrared spectroscopy technique for monitoring hot melt extrusion. International Journal of Pharmaceutics 2015; 496: 117-123.

https://doi.org/10.1016/j.jpharm.2015.07.025

[2] Moghaddam L, Rintoul L, Halley PJ, George GA, Fredericks PM. Insitu monitoring by fibre-optic near infrared spectroscopy and rheometry of maleic anhydride grafting to polypropylene in a laboratory scale reactive extruder. Polymer Testing 2012; 31: 155163.

https://doi.org/10.1016/j.polymertesting.2011.10.002

[3] McLauchlin AR, Ghita O, Gahkani A. Quantification of PLA contamination in PET during injection moulding by in-line near infrared spectroscopy. Polymer Testing 2014; 38: 46-52. https://doi.org/10.1016/i.polymertesting.2014.06.007

[4] Barbin DF, Valous NA, Dias AP, Camisa J, Hirooka EY, Yamashita F. VIS-near infrared spectroscopy as a process analytical technology for compositional characterization of film biopolymers and correlation with their mechanical properties. Material Science and Engineering C 2015; 56: 274-279.

https://doi.org/10.1016/j.msec.2015.06.029

[5] Rohe T, Becker W, Kölle S, Eisenreich N, Eyerer P. Near infrared (near infrared) spectroscopy for in-line monitoring of polymer extrusion processes. Talanta 1999; 50: 283-290. https://doi.org/10.1016/S0039-9140(99)00035-1
[6] Stankovic M, Frijlink HW, Hinrichs WLJ. Polymeric formulations for drug release prepared by hot melt extrusion: application and characterization. Drug Discovery Today 2015; 20: 812-823. https://doi.org/10.1016/i.drudis.2015.01.012

[7] MarkI D, Wahl PR, Menezes JC, Koller DM, Kavsek B, Francois K, Roblegg E, Khinast JG. Supervisory control system for monitoring a pharmaceutical hot melt extrusion process. AAPS PharmSciTech 2013; 14(3): 1034-1044.

https://doi.org/10.1208/s12249-013-9992-7

[8] Scherzer T, Müller S, Mehnert R, Volland A, Lucht H. In-line monitoring of the conversion in photopolymerized acrylate coatings on polymer foils using near infrared spectroscopy. Polymer 2005; 46: 7072-7081.

https://doi.org/10.1016/i.polymer.2005.05.142

[9] Almeida A, Saerens L, De Beer T, Remon JP, Vervaet C. Upscaling and in-line process monitoring via spectroscopic techniques of ethylene vinyl acetate hot-melt extruded formulations. International Journal of Pharmaceutics 2012; 439: 223-229.

https://doi.org/10.1016/i.ipharm.2012.09.037

[10] Howland H, Hoag SW. Analysis of curing of a sustained release coating formulation by application of near infrared spectroscopy to monitor changes physical-mechanical properties. International Journal of Pharmaceutics 2013; 452: 82-91.

\section{https://doi.org/10.1016/i.ipharm.2013.04.035}

[11] Duemichen E, Javdanitehran M, Erdmann M, Trappe V, Sturm $H$ Braun $U$, Ziegmann $G$. Analyzing the network formation and curing kinetics of epoxy resins in situ near-infrared measurements with variable heating rates. Thermochimica Acta $2015 ; 616$ : 46-60 https://doi.org/10.1016/j.tca.2015.08.008

[12] Li G, Huang Z, Li P, Xin C, Jia X, Wang B, He Y, Ryu S, Yang X Curing kinetics and mechanism of polysulfone nanofibrous 
membranes toughened epoxy/amine systems using isothermal DSC and near infrared. Thermochimica Acta 2010; 497: 27-34. https://doi.org/10.1016/i.tca.2009.08.005

[13] Yamasaki $\mathrm{H}$, Morita S. Temperature dependence of isothermal curing reaction of epoxy resin studied by modulated differential scanning calorimetry. Journal of Molecular Science 2015; 1-7.

[14] Yamasaki H, Morita S. Identification of the epoxy curing mechanism under isothermal conditions by thermal analysis and infrared spectroscopy. Journal of Molecular Structure 2014; 164-170. https://doi.org/10.1016/i.molstruc.2014.01.037

[15] Kortaberria G, Arruti P, Gabilondo N, Mondragon I. Curing of an epoxy resin modified poly (methyl methacrylate) monitored by simultaneous dielectric/near infrared spectroscopics. European Polymer Journal 2004; 40: 129-136. https://doi.org/10.1016/i.eurpolymj.2003.09.009

[16] Vargas MA, Sachsenheimer K, Guthausen G. In-situ investigations of the curing of a polyester resin. Polymer Testing 2012; 31: 127-135. https://doi.org/10.1016/i.polymertesting.2011.10.004

[17] Wang Y, Steinhoff B, Brinkmann C, Alig I. In-line monitoring of the thermal degradation of poly(L-lactic acid) during melt extrusion by UVvis spectroscopy. Polymer 2008; 49: 1257-1265. https://doi.org/10.1016/j.polymer.2008.01.010

[18] Coates PD, Barnes SE, Sibley MG, Brown EC, Edwards HGM, Scowen IJ. In-process vibrational spectroscopy and ultrasound measurements in polymer extrusion. Polymer 2003; 44: 5937-5949. https://doi.org/10.1016/S0032-3861(03)00544-5

[19] Kann Y, Shurgalin M, Krishnaswamy RK. FTIR spectroscopy for analysis of crystallinity of poly(3-hydroxybutyrate-co-4 hydroxybutyrate) polymers and its utilization in evaluation of aging, orientation and composition. Polymer Testing 2014; 40: 218-224. https://doi.org/10.1016/i.polymertesting.2014.09.009

[20] Cui Z, Coletta C, Rebois R, Baiz S, Gervais M, Goubard F, Aubert $\mathrm{PH}$, Dazzi A, Remita S. Radiation-induced reduction-polymerization route for the synthesis of PEDOT conducting polymers. Radiation OPhysics and Chemistry 2016; 119: 157-166. https://doi.org/10.1016/j.radphyschem.2015.10.011

[21] Allison GG. Application of Fourier Transform Mid-Infrared Spectroscopy (FTIR) for research into Biomass Feed-Stocks. InRech 2011; 71-88, ISBN: 978-953-307-232-5.

[22] Hell J, Prückler M, Danner L, Henniges U, Apprich S, Rosenau T, Kneifel W, Böhmdorfer S. A comparions between near-infrared (near infrared) and mid-infrared (ATR-FTIR) spectroscopy for the multivariate determination of compositional properties in wheat bran samples. Food Control 2016; 60: 365-369. https://doi.org/10.1016/j.foodcont.2015.08.003

[23] Warren FJ, Gidley MJ, Flanagan BM. Infrared spectroscopy as a tool to characterise starch ordered structure-a joint FTIR-ATR, NMR, XRD and DSC study. Carbohydrate Polymers 2016; 139: 35-42. https://doi.org/10.1016/i.carbpol.2015.11.066
[24] Li Y, Jing J. A consensus PLS method based on diverse wavelength variables models for analysis of near-infrared spectra. Chemometrics and Intelligent Laboratory Systems 2014; 130: 45-49.

https://doi.org/10.1016/j.chemolab.2013.10.005

[25] Jiang H, Liu G, Mei C, Yu S, Xiao X, Ding Y. Measurement of process variables in solid-state fermentation of wheat straw using FT-near infrared spectroscopy and synergy interval PLS algorithm Spectrochimica Acta Part A: Molecular and Biomolecular Spectroscopy 2012; 97: 277-283. https://doi.org/10.1016/i.saa.2012.06.024

[26] Fernandez-Espinosa AJ. Combining PLS regression with portable near infrared spectroscopy to on-line monitor quality parameters in intact olives for determining optimal harvesting time. Talanta 2016; 148: $216-228$.

https://doi.org/10.1016/i.talanta.2015.10.084

[27] Frizon CNT, Oliveira GA Perusselo CA Peralta-Zamora PG Camlofski AMO, Rossa ÜB, Hoffmann-Ribani R. Determination of total phenolic compounds in yerba mate (Ilex paraguariensis) combining near infrared spectroscopy (near infrared) and multivariate analysis. LWT-Food Science and Technology 2015; 60: 795-801. https://doi.org/10.1016/i.lwt.2014.10.030

[28] Grassi S, Amigo JM, Lyndgaard CB, Foschino R, Casiraghi E. Beer fermentation: Monitoring of process parameters by FT-near infrared and multivariate data analysis. Food Chemistry 2014; 155: 279-286. https://doi.org/10.1016/i.foodchem.2014.01.060

[29] Olarewaju OO, Bertling I, Magwaza LS. Non-destructive evaluation of avocado fruit maturity using near infrared spectroscopy and PLS regression models. Scientia Horticulturae 2016; 199: 229-236. https://doi.org/10.1016/j.scienta.2015.12.047

[30] Geladi P, Kowalski BR. Partial least-squares regression: a tutorial. Anal Chim Acta 1986; 185: 1-17. https://doi.org/10.1016/0003-2670(86)80028-9

[31] Mittag HJ. Schätzung von Parametern. in Statistik, edited by Mittag HJ, Springer-Verlag, Berlin Heidelberg 2011; pp. 175-184. https://doi.org/10.1007/978-3-642-17846-7 14

[32] Becker W, Hochrein T. Optische Spektroskopie, in Prozessmesstechnik in der Kunststoffaufbereitung, edited by Hochrein T, Alig I, Vogel Business Media, Würzburg, 2011; pp. 217 262.

[33] Huber F, Herrmann A, Meyer F, Vogel J, Vollhardt K. Grundlagen zur Modellierung von Strukturgleichungen, in Kausalmodellierung mit Partial Least Square, edited by Huber F, Herrmann A, Meyer F, Voge J, Vollhardt K. GWV Fachverlage $\mathrm{GmbH}$, Wiesbaden, 2007; pp. 3-16.

[34] http://www.originlab.de/doc/Origin-Help/Partial-Least-Square, 20.06.2015

(c) 2017 Lepschi et al.; Licensee Lifescience Global.

This is an open access article licensed under the terms of the Creative Commons Attribution Non-Commercial License (http://creativecommons.org/licenses/by-nc/3.0/) which permits unrestricted, non-commercial use, distribution and reproduction in any medium, provided the work is properly cited. 